\title{
A COMPARATIVE STUDY ON 4-WAY ROLLER USED IN ROLLING MILL
}

\author{
NILESH NIRWAN ${ }^{1} \&$ DR. SANDEEP SALODKAR ${ }^{2}$

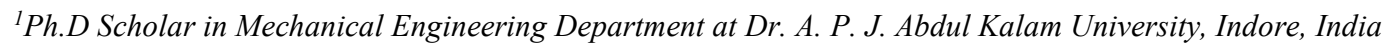 \\ ${ }^{2}$ Vice Chancellor at Dr. A. P. J. Abdul Kalam University, Indore, India
}

\begin{abstract}
In this article a review on 4 way roller surface improvement performance is studied. Methods of quality improvement of a roller products was performed. The main focus for investigation on the roller surfaces of the cold roll mill are influencing high quality of rolled products which involved rolling process, rolling equipments and its corresponding tools. After studying on different review papers it is found that friction is occurred at some points where the defects are arises on the outer surface of the rollers. Hence by the help of an experimental investigation the gap between two rollers measured and its effect on roll transverse vibration was analyzed. On the roller surface we have to determine the defective points like rusting, scaling, scratches, zipper cracks which cause Alligatoring and prominent surface ruptures. Although it is difficult to completely prevent these defects but we have studied to minimize these defects by some methods which are continual varying crown, non-parallel gap between the rolls and cambering of rolls. Using these techniques we rectify the defects occurred on the 4-way rollers used in rolling mill.
\end{abstract}

KEYWORDS: Experimental Investigation, Cold roll, Surface defects, Continual varying crown, Cambering of rolls

Received: Oct 03, 2020; Accepted: Oct 23, 2020; Published: Jan 09, 2021; Paper Id.: IJMPERDDEC202080

\section{INTRODUCTION}

Increasing quality requirements and competition in the market forces the producers to take steps aimed at rolling wider strips, using heavier coils, with maximum yield [1]. Also the producers are trying to reduce the number of necessary technological operations and minimize technological waste [1]. These activities are aimed at improving the economic efficiency of the manufacturing process [1]. Increasing competitiveness of their products besides the economic aspects of the production process is closely linked with the quality of the offered product which along with the price is a key to the possibility of finding customers [1]. Efforts to reduce costs and improve quality are to some extent the initiating and steering factor in modernization activities [1].

The quality of the final rolled sheet greatly depends on its thickness deviation [2]. This statement is applicable for thin and thick sheets, rolled on hot and cold rolling mills [2]. Sheet thickness falls into two categories: longitudinal and cross (transverse) thickness [2]. Both of these parameters define the final flatness of the sheet [2]. The initial reduction of the slab, taking place on hot rolling, makes a significant influence on the geometric parameters of the metal [2]. No matter the

Rolled plate is the final product or just the first step in getting a thin strip - the longitudinal and cross variation in thickness is laid in primary rolling passes [2]. Cold rolled thin metallic strips have wide applications in the 
electronics and instrument industries [3]. These industries require exceptional accuracy of the strip, as the devices that utilize the cold rolled thin strip are required to have an accurate and precise profile and flatness [3]. In these devices, the strip is used as an electrical contact and a signal receiver [3]. In industry, the variety of cold rolled thin strip applications with gauges of less than $0.5 \mathrm{~mm}$ thick has increased, and the demand for high quality of thin strips has compelled the industry to attain higher performance standards in order to remain competitive [3].

For instance, by reducing material thickness from $0.2 \mathrm{~mm}$ to $0.1 \mathrm{~mm}$, both the cost and the component weight can be significantly reduced [3]. Producing thinner strips, however, requires more money and time [3]. On the other hand, because of the elastic deformation of the rolls during the rolling process, maintaining thin strip shape and profile and dimensional accuracy is difficult [3]. In order to sustain the market competitiveness of strip rolling, there is a strong focus on improving the manufacturing quality and productivity [3]. Two of the most critical characteristics which have a great influence on both the rolling process and quality of the product are the shape and profile of the thin strip [3]. The quality of the strip is mainly governed by the optimization of the rolling parameters, such as the rolling speed, reduction, strip width, friction, roll pair cross angle, and work roll shifting value [3]. Thus, if the rolling parameters are imperfectly specified, the loading force causes elastic deflections of the rolls which has an effect on the shape and profile of the rolled strip and thus its quality [3]. A variety of advanced control shape rolling mills have been designed [3]. The strip profile can be controlled by varying the shape of the gap between the work rolls by using advanced rolling mills [3]. Such roll gap profile control can be carried out on mills equipped with work roll crossing and by making use of a combination of roll axial shifting and asymmetrical rolling [3]. One above another roller is used to reduce the centre deflection of the roller.

\section{PROBLEM STATEMENT}

When the job or raw material is inserted into the rolling machine it gives a reverse effect to the rollers, as the purpose of machine is to reduce the thickness of the work material during the roll passes the workpiece also deflects the roller. Thus, to eliminate the bending effect which gives on roller we have to apply different strategies. When the workpiece is inserted into a gap of two rollers there is a diverse bend on the rollers as well as on a workpiece. Requirement of minimum thickness of workpiece is always available but the formation of bend in a rollers will get reduce the life of end point bearings. So in most of the journals authors are focused on the reduction of bending of two up and down rollers. This bend curve are appeared at the edges of rollers and these bending provide a deviation across the whole length of rollers. Many of the researcher work on reverse bending which is used to compensate work roll bend caused by roll force and to hold back work rolls against the workpiece.

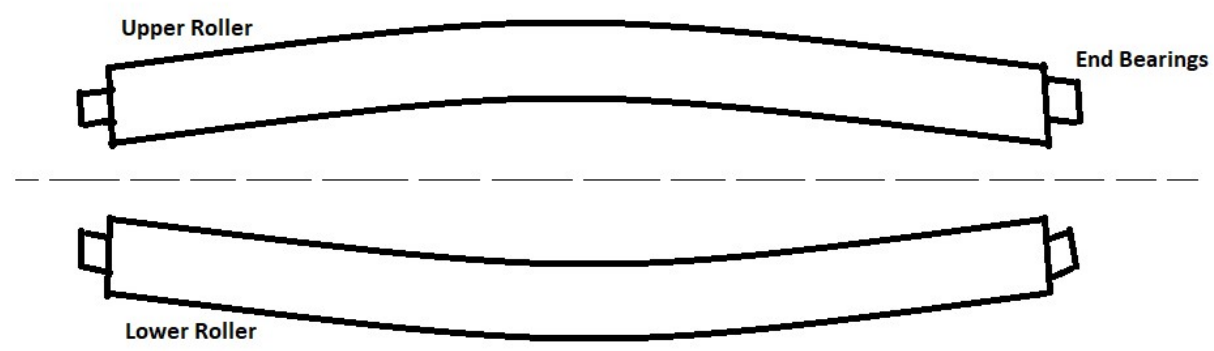

Figure 1: Reverse bending effect on both side of rollers 


\section{METHODS TO IMPROVE THE QUALITY OF ROLLERS}

In an area of quality improvement most of the researcher are focused on the elimination of shape defects, and improvement of the surface quality. Among many methods of improving the quality of rollers in rolling mill products three main directions of actions can be identified, the efforts are aimed to remove or limiting the formation of defects, this will achieve a closer dimensional tolerances and obtain uniform distribution of thickness over the entire length of workpiece.

\section{The actions are being taken in three main directions:}

In the rolling mill equipments such as reduce the vibration which will fix the rigidity of the machine, types of bearing used at end of rollers, power transmission from motors to roller and multiple rolling system.In the selection of machine components and implementing their process such as various type of components should be selected so that there will be reduction in bend at the centre of the rollers. Selection of process parameters which is used in the rolling mill. Process of cooling at the outer surface of rollers and the end bearings.

In the field of the rolling equipments such as roll materials, profile of the rollers, way of mechanism to reduce the thickness of workpiece. These have a major impact for making the improvement in the rolling machine. With these all three main directions it will minimize the defects of rollers associated with different variable thickness of the length of rollers. By comparing the various studies of researchers they will reduce the gap of the two rollers with minimum passes over the production of every products. The width of the band of raw materials sometime never reduce because of hard materials properties with these drawback we have to analyses the raw materials which are normally taken into the gap of two rollers. In many of the industries raw materials can be taken as pig iron, mild steel, alloys of steel or iron. These materials have the ductile properties to reduce or compress the thickness also they have the plasticity in their ores which is capable of making fine thin sheets. In rolling process the main disadvantage of making thin sheets are driving forces from motors to the rolling components which affecting the formation of dimensional inaccuracies of the products. The driving torque get transferred from flywheel to the bearing of the rollers and then rollers are moving in fast way to reduce down the non-elastic strain of the raw materials. Total elastic strain causes the significant change in the roll region. Strain has the linear characteristics in the range of normal loads occurred on to the rollers.

\section{CURRENT ROLLING SYSTEM}

If we have to reduce the thickness of a raw material then rolling forces have increases to the workpiece for that purpose we have to increase the diameter of the roller but very high diameter of rollers will get increase the overall dimension of the rolling machine hence, the system will becomes bulky and uneconomical for industries. 


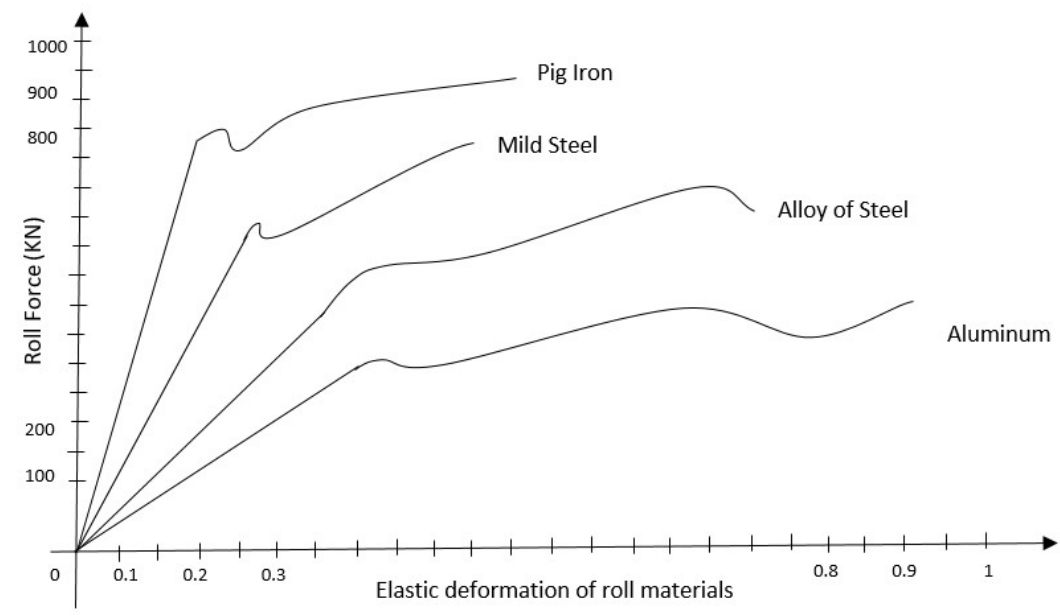

Figure 2: Applied roll force to various raw materials

This type of approach shows that whenever rolling force applied on the various raw materials it will increase the roll gap insignificantly. In addition to improve the stiffness of roller we have reduce total roll force acting on the raw materials. Reduction the value of roll force is one of the method to reduce the change in the roll gap of rollers in the rolling machine. The plasticity of different metals are defined by manufactured products therefore reduction in roll force occurred only when the interaction between roll areas is to be reduces. This type of roll work required smaller diameter in rolling machine but reducing the diameter of rollers increases the stiffness of the rollers. The stiffness should be limited to increase the efficient way of manufacturing proper products. To improve the quality of rollers we have to increase the no. of rollers i.e. used of multi rolling system in a given rolling machine. By the use of multi rolling system it will increase the stiffness of rollers and make system at a rigid point.

In these system work roll are smaller in diameter hence another multi rollers are used to give the roll force on these two smaller rollers. It reduces the centre bend of this smaller rollers also it allows to minimize the stiffness of work roll. Increasing the no. of working rolls does not mean to achieve appropriate quality work of roll strips. Roll strips are made after raw material is passes through the rolling machine again and again to acquire a proper dimensions, these accurate dimension material is called as the roll strips. Whenever we are increasing the multi rollers to achieve the required stability and machine efficiency it changes the dimensional accuracy because of non-homogeneity in the entire rolling process and its properties are also affect the desired quality of acquired products. In modern multi roll system equipped with proper measurement control with high technical solutions. This will allows a proper quality products. All these techniques we are added in rolling machine will compensate the reduction in bend of the rollers, stiffness of the roller materials and shape of rollers. 


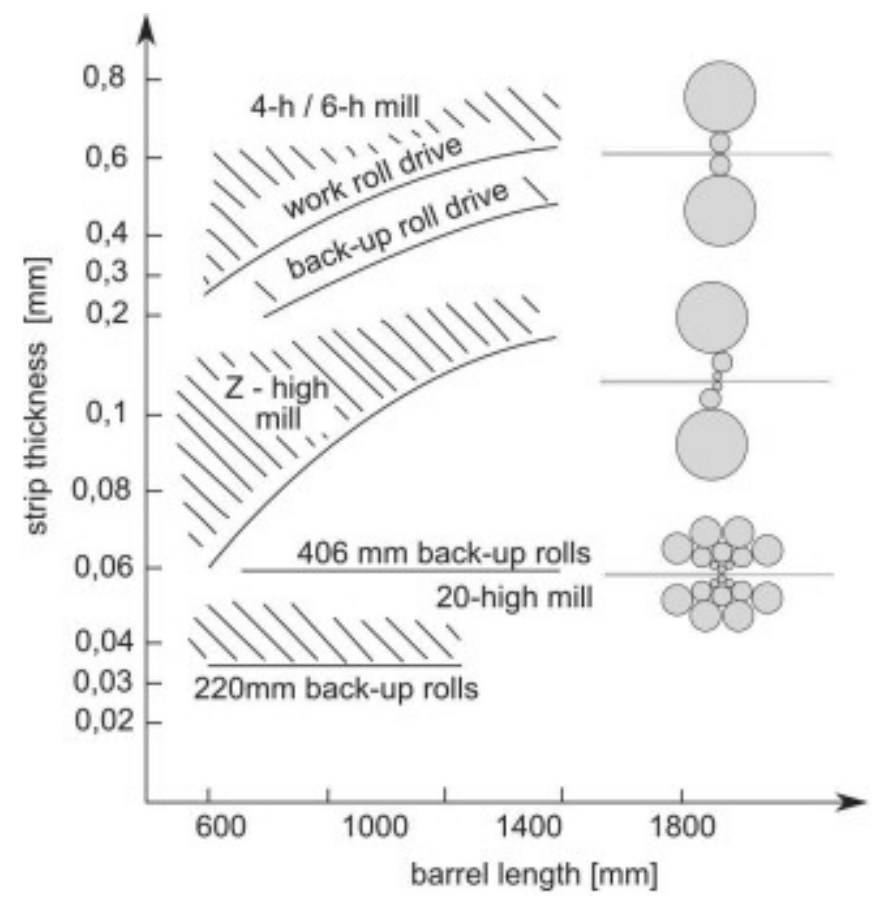

Figure 3: Multiple rollers with change in roll strip thickness

The experiment was carried out in real production conditions on the roll forming production line [4]. The production line was specially prepared with the equipment for forming forces measuring on the rolls and the roll stands deformation on forming stations [4]. It was also prepared with other necessary resources for implementation of the design of experiment [4].

\section{CONTROLLING IN ROLL GAP OF ROLLERS}

It is very difficult to remove the shape defects of rollers in collaboration with the change in deformation of irregular shape of raw materials or roll strips. Lot of study has taken out to control and monitoring the gap of rollers by maintain uniform distance between them. The most popular method to reduce or compensate the centre deflection of the roller is introduce a same profile rollers for producing a back force on the smaller rollers which are indirect contact with the raw materials. In few of the research articles it is found that a cylindrical profile is used instead of the plain similar smaller roller profile to reduce the centre bend but by the maximum no. of cycle of rotation of a rollers the rollers are bend a centre and their profile is change to lower parabolic form (Fig. 4). This drawback is reduce the life of roller. Due to this negative crown deflection of rollers the maintenance cost of the rollers are increases. For special purpose manufactured of product positive crown effect is needed to the roll strip hence after completing 32 mega cycles this type of rollers can be used to acquire a proper shape. There is also another similar method to achieve a proper shape of rollers. In this method hydraulic cylinder is connected to the rollers when rolling is started hydraulic cylinder will pull back the small rollers. This method is more versatile than the previous one as it is easy is to control the pressure of cylinder for the desired pull back bending effect of small rollers. It allows to maintain the continuous pull back bending effect to a smaller rollers and its profile is maintain to produce the desired product with proper dimensions.

Another way to reduce the centre deflection of rollers is to use the pair of cross rolls in a rolling mill. In cross roll pair of rolling mill rollers are shifted to an inclined position with respect to the straight alignment of smaller rollers hence the gap between upper roller and lower roller is reduce by the parabolic shape of cylindrical rollers. The axis alignment are parallel to 
the smaller rollers but it will shifted normally to $12^{0}$ to $15^{\circ}$. This operation takes axial shifting of rollers with respect to the axis of roll strips. Sometimes at the contact point of these two rollers friction is arises so with these axial shifting of rollers can reduce the wear between the contacting rollers with edges of the band of rollers. Whenever rolling process is going on various raw materials with different type of thickness are rolled. To protect the work roll wear at one point, there should be a need of optimize program which can be create an appropriate sequence of rolling. Alternatively, with the help of these program the rolling process can be done in any order with proper directions, since the distribution of work roll is proceed out by optimizing of rolling mill hence the distribution of wear is carried in uniform directions. The main application of this type of system is to connect different types of rolls profile to each other and allow to control the gap between upper and lower rollers. Combination of roll pair and roll shifting method will maintain the gap between upper and lower rollers also it allow to control the profile shape of rollers for longer interrepair cycle of rollers by reducing wear due to axial movements of rollers.

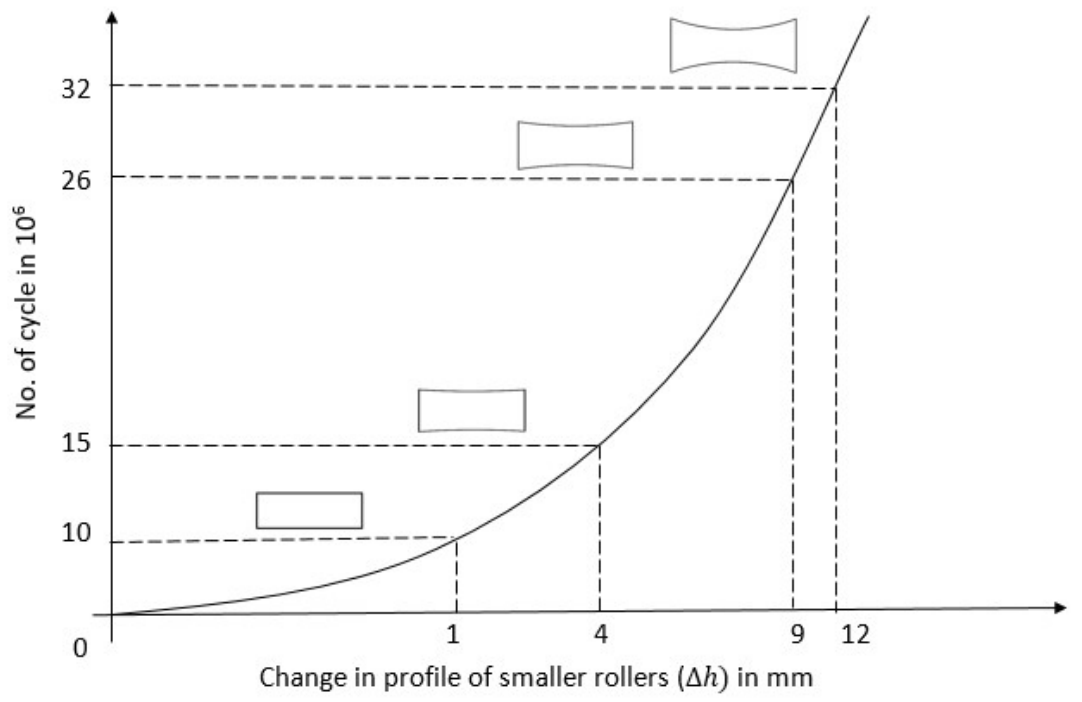

Figure 4: Dimensional deviation in a profile of rollers

As an important basic part of the machinery industry, the roller bearing has been widely used in many fields of national industries, such as aerospace, transportation, and machinery manufacturing [5]. The roller bearing has the function of supporting and reducing friction and is one of the most indispensable and vulnerable parts in rotating machinery [5]. The quality of the roller surface directly affects the performance and service life of mechanical equipment [5]. Therefore, accurately and efficiently inspecting the surface defects of rollers is of great significance in improving the yield of rollers, the stable operation of machinery, and the production of enterprises [5].

\section{SOLUTION OF DEFECTS IN ROLLING EQUIPMENT}

Rolling equipment is one of the major device to force raw materials into the rolling mill while transmitting force it affects the dimensional inaccuracies of the rollers. Basically the roll force is transferred from motors to bearing and then to the rollers. The construction of rolling machine is massive and therefore its total elastic strain causes the significant gap between the rollers. This strain shows a greater sensitivity to a high applied load due to play deletion and matching the mating surfaces.

There are several defects occurred while rolling the raw materials into the rollers such as Plate rolling defects, Barrel defects, Reel defects, Skewing defects and Conical defects. All these defects can be removed by proper optimize study of 
rolling process which will help to improve the rolling equipments. Plate rolling defects are occurred when anyone using plate roll machine with upper and lower limit capacity of machine. When rolling process start camber is built at the surface of roller to compensate for the deflection when machine is under high load. Most of the rolling machine have the range of deflection at the middle of rollers, within these range they roll perfectly without any defects. Generally these camber is calculated for $60 \%$ of the machine capacity if material is having high thickness then bending force is come across over the entire width of the plate. This will clear the idea about plate rolling any material rated up to the range of $60 \%$ of machine capacity should be rolled perfectly straight with no defects. If material will go beyond this limit of $60 \%$ capacity then it will start the occurrence of few defect parts along the rolled part. It is small at first then gradually it start bigger further move away from $60 \%$ capacity of machine. By the use of thicker material the rolls are deflected past straight.

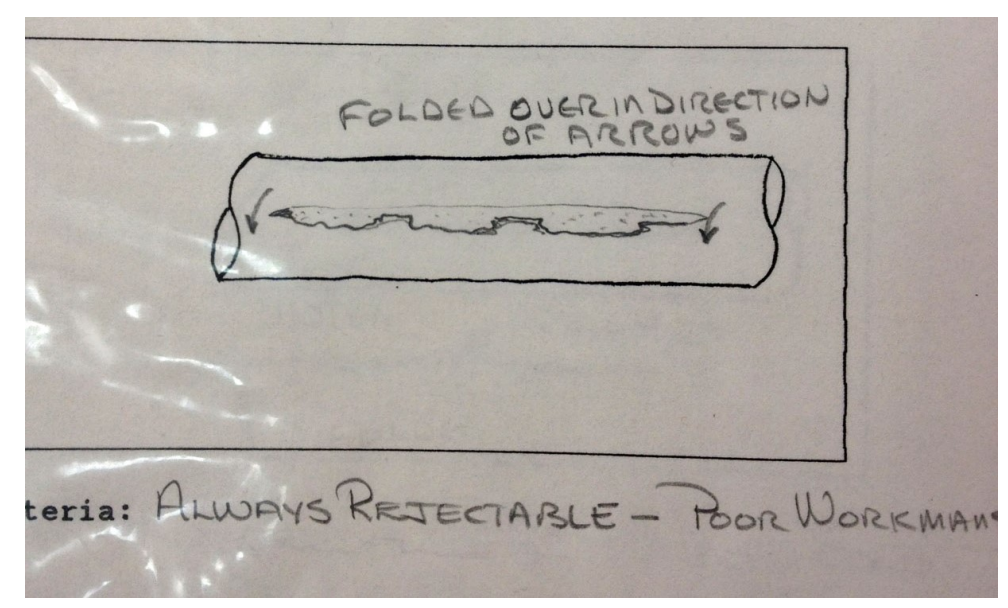

Figure 5: Barrel Effect on the edge of roller

This will cause more deflection at middle of rollers and close of thickness at the end corner of rollers. Thus these plate roll defects can be avoided by using proper setup of operations. Rolling process start continuous and the material will get straight with reducing its thickness after no. of passes are gone defects are again changes. Due to maximum no. of cycles Barrel defects happen over the rollers. The plate is thicker it deflects all the camber out while the rolling process start. It is tighter at the outside ends of material and looser at the middle. To compensate this type of defects most of the industries are tried to pinch lower pressure so that when rolling process start it deflect the roll less. The downside requires an operator to leave a long flat side pre bend. There is another way to reduce this bend is shimming. Shimming is the process in which an operator can use a similar type of material along edge of the material at the centre of the plate. The shim or cardboard is placed at the top of the raw material it will changes the chamber of the roll making it bigger at the centre when the roll is deflected during bending a straight seem is taken at the centre of the plate. It is deflect the roll but maintain the centre bend of the raw material at its place. The thickness and width of the shim is adjusted as per the requirement of the operator. 


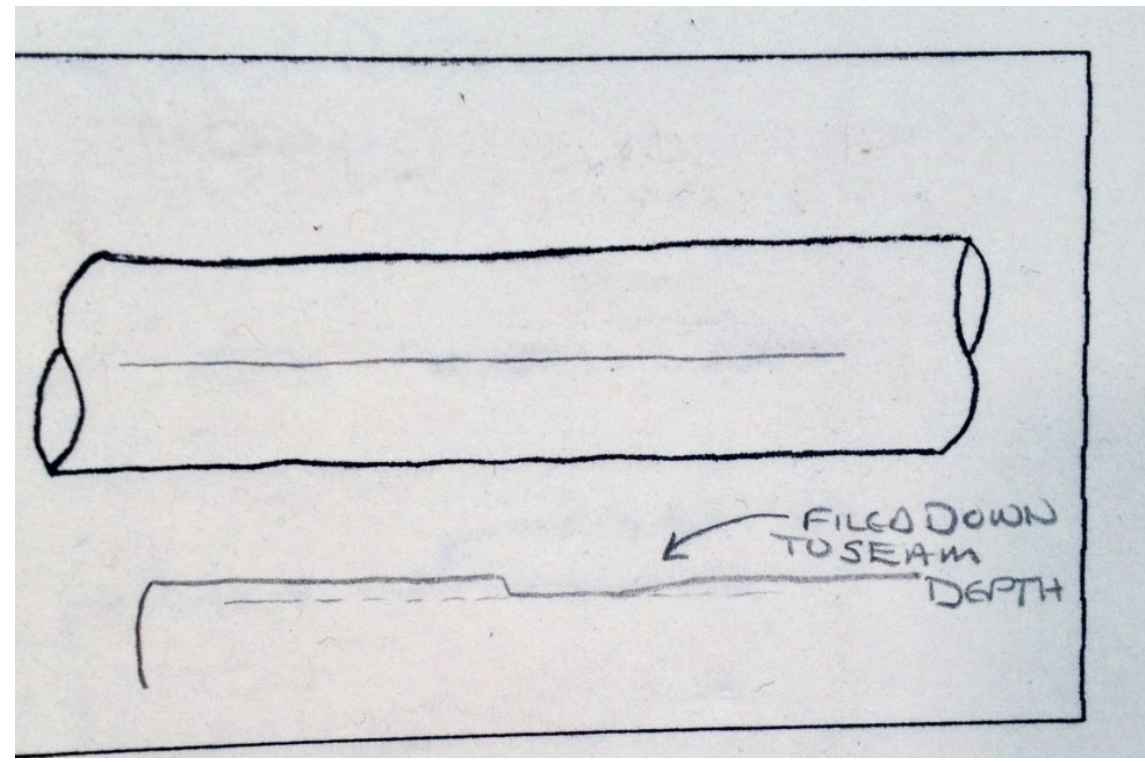

Figure 6: Reel Effect on the edge of roller

There is another defect opposite of the barrel defect. It happen in the material which is thinner and not use for cambered. The raw material inserted into the rolling machine will not deflect at the centre therefore these thinner materials are camber out material. It is tighter at the middle and loss at the outer ends of the rollers. To compensate this type of bend we can try to increase the pinching pressure to deflect more at the outer ends by taking straightness at the entire width of the raw material. If the material is rolled very thin it is possible to use a controllable little pressure at the middle of the plates or raw materials, this will cause the rippling effect on the plate. If the deflection again very thin at the middle of the plate then we have use shimming effect on the plate to make it straight. Instead of inserting card board at the centre we have to insert it towards the outer edges of the plate. It work is similar but opposite of the solution of barrel effects.

In a similar way there are another two defects are most commonly occurred at the raw material while reducing the thickness of the materials. Skewing defects are occurred when the plate rolled skewed to a straight but instead the edges of the plates are lining up and it will shifted to left or right. Normally this type of defects are happen if the rolls are not parallel means the gap between two rollers is not uniform. Another one is the conical defects if one side of the roll is tighter than the other side then raw material oppose the loose roller. If this defects occurred then material is shown in a conical shape. To avoid this type of the defects we have inspect the assemble parts like nuts, bolts, screws etc. It is the easiest adjustment that can be made by operator. There are some other solution for correcting the bend effect of rollers such as purchasing a second or third interchangeable top or bottom roll with different camber. Sometime interchanging of the components may affect the maintenance cost of the machine. In some of the industries operators are used another material to wrap on the existing roller to make the diameter larger in the centre or at the outer edges of the rollers. This method work well but wrapping of material is not a last long solution to increase the accuracy and it have to be replaced. 


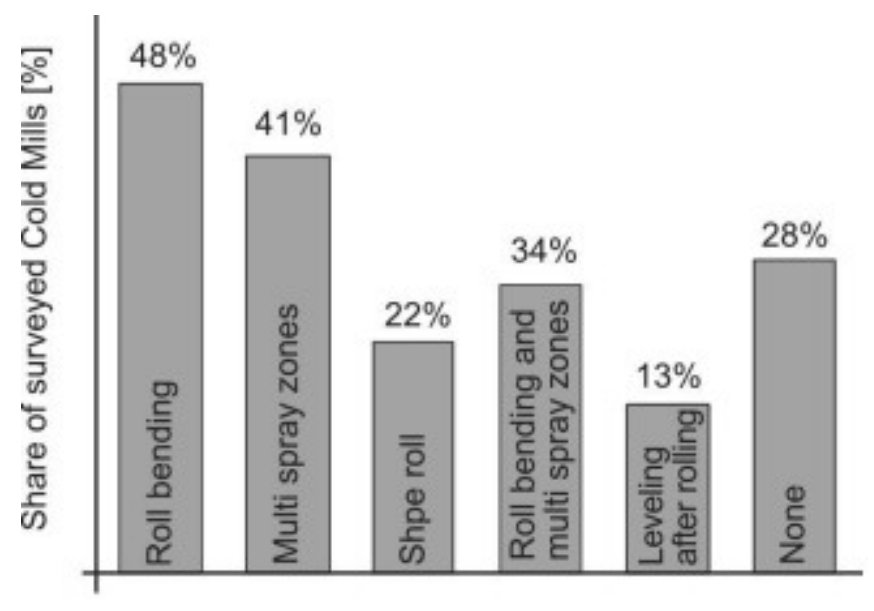

Methods used for flatness control

Figure 7: Most popular shape control methods as indicated in North American cold rolling mills market research

Roll is a tool taking all kind of stresses, loads from normal and abnormal wear in a rolling process. Rolls are required to carry out the heavy work required in industry necessary for the reduction of thickness of any type of raw material, sheet material, plates etc. Rolls are always give a better performance during complete rolling process. Roll should never be break, spall or wearied during the work process, it will not cause any problem while doing rolling process of raw materials such as steel, aluminum, pig iron etc.

\section{CONTEMPORARY REMARKS ON ROLL MAKING}

Rollers are the tool which are important and mostly involved in rolling process. Surface quality of manufactured rollers significantly depends on the tool properties and its functional characteristics. In the process of rolling rolls get worn which cause a degradation of its working surface. Due to this worn effect a small wear of texture is generated a the surface of roller and when any plastic material is proceed on the rolling process it will get transfer (Micro plastic materials) on the surface of the roll strip. Rather comparing with wear effect we can also think on the roll behavior under the influence of cyclic load deviation. The drive transmission of torque in cyclic process are associated bending and twisting moment at roll gap deformation. It will affect the improper design of raw material over the continuous rolling process. Desirable counter action is needed to improve the products coming from rolling mill machine. Therefore a new solution in the field of work roll cross section profile and its construction is design as a contemporary solution. A different approach to acquire a convex crown on rollers are to be implemented with variable profile geometry.

This type of profile can be superimposed on the surface of the work rolls or back up rolls. Such type of shape roll with proper controlling on upper and down crown profile allow to reduce a roll gap in any ways. The identification, selection, design desirability, and promotion of locally modified tools is made possible through the strengthening and redesigning of machine vital components, the improvement of welder's craftsmanship and adequate enhancement of local manufacturing processes through the use of locally improved work tools and machines [6]. Reverse bending is used to compensate work roll bend caused by roll force and to hold back work rolls against support ones [7]. For the convenience of installation work roller, there is clearance between work roller bearing seat and mill house in four high mill, which makes work roller in an unstable state when there is no fixed side force on it [8]. Trends of improving the equipment units of the continuous rolling are determined by the desire to increase the efficiency of the process and effectiveness of use of equipment, to expand the range of 
products, which are potentially suitable for the processing on particular equipment [9]. When a new roll forming machine is designed the tool designer must decide how many forming steps are required to form the profile [10]. The compatibility of deformation between the reinforcement and metal matrix has significant effects on the strength and ductile of composite [11]. The opposing spiral protrusions and valleys of the upper and lower rolls in this tool are respectively made according to the left and right helix [12]. The research shows the findings of the past researchers in the field of cold rolling process and the future work about the rolling field [13]. The rolling mill consist of rolls as the main tool, there are various rolling mills depends upon the number of rolls used in the machine [13]. Roll clustering is necessary to prevent excessive deflections of the rolls during the conditions of relatively higher loading, as is the case when cold rolling higher strength or thinner gauge metals [14]. As the roller recirculates between raceway and the reverser, its dynamic state changes dramatically [15]. The roller in the raceway is preloaded, while it is free in the reverser [15]. These changes lead to the collision and blockage of the roller at the exit and the entrance of the reverser, and leading to increase of friction resistance and the noise of the guide pair [15]. In the process of rolling ribbed bars using the longitudinal band separation technology, the slitting pass wear (by roll groove abrasion and burnout) is an especially important issue [16]. The determination of the magnitude of pass wear in this process can prevent many difficulties encountered when running it and ensure that a finished product is obtained, which meets the requirements of applicable acceptance standards [16]. It is a good practice to use the principle of the three-stand mill modeling developed at investigation of rolling mills with different number of the continuous stands [17]. The shape pattern recognition model is a basic model of shape theory [18]. It decomposes the deviation of the measuring shape and the target shape into a series of standard patterns, providing the basis for shape control [18]. Rolling is a process of reducing the thickness or changing the cross section of long workpiece through compressive forces applied by a set of rolls; thus the process is similar to rolling dough with a rolling pin to reduce the dough's thickness [19]. Finite-element (FE) computer simulation can be used to predict the deformation and final product geometry, hence, reduce the design time and cost [20]. Due to the inherent complexity of the cold roll-forming process, machine design procedures have remained highly empirical [21]. If a large number of rolls are used in the tool design, the applied bending is very gradual and unwanted strains are reduced [22]. In roll forming, the longitudinal edge strain is considered to be related to product defects such as bow, twist and end flare [23]. Process and part shape parameters have been shown to significantly influence peak longitudinal edge strain, and the link between process and product parameters, longitudinal edge strain and shape defects needs to be understood for the roll forming [23]. The objective with this study is to investigate a new tooling concept that makes it possible to roll form hat-profiles with variable depth and width in longitudinal direction [24]. To evaluate the new tooling concept three different hat-profiles, one with constant cross-section and two with variable cross-section in depth and width, are roll-formed and the tolerances from fifty profiles of each kind are compared [24].

\section{CONCLUSIONS}

Defects deriving from the implementations of the rolling process can be eliminated or at least their impact on the profile surface of rollers can be reduced. Such type of action can be implemented with the use latest technology itself. It is process which understood the different parameters used in rolling mill and appropriate selection of tool and their geometric features for quality improve mentation in rollers. Defects that are mention in this paper are mainly resulting from the geometry of products perfectly flat with uniform cross sections. All the defects which are giving in this article have been experienced by various roll mill industries from several group of factors. Factors which are affecting on the dimensional tolerances of products in the process of 4-way cold rolling. Available rolling equipment solutions, way of technological process 
realizations, tools used in the applied solution are the significant upgrade in existing technology of the rollers in rolling mill. It is possible to choose the rolling equipment in a way to improve the quality of products in a specific range of shape and tolerances. However in most of the industries this process is conducting on available machineries and hence it is impossible to alter these process.

Technological processes that are being carried out is properly realize comparing to various articles studies by different industrial engineer's. This will allows a certain level of quality arising from technical possibilities. If the process realization is going on wrong way then it may reduce the achievable qualities. In the analysis of all the comparable studies it is clear that assumed process is always realize in correct manner. The important element in the manufacturing of roll mill rollers are influence obtaining in the dimensional tolerances of roll. The dimensions of roll has an impact on the quality of products. The manufacturing quality of the roll and its features gives the great possibilities in the field of narrowing obtained dimensional deviations. It seems that controlling of roll deflection is the simplest and effective way to improve the quality of rolled products.

\section{REFERENCES}

1. W. Soszyński and A. Studnicka, “A review of contemporary solutions for cold rolling that allow quality improvement," J. Achiev. Mater. Manuf. Eng., vol. 55, no. 2, pp. 810-816, 2012.

2. E. A. Maklakova, A. S. Maklakov, V. R. Gasiyarov, and S. S. Voronin, "The work roll bending control system of the hot plate rolling mill," Procedia Eng., vol. 129, no. December, pp. 37-41, 2015, doi: 10.1016/j.proeng.2015.12.005.

3. H. Tibar and Z. Jiang, "Improving Thin Strip Profile Using Work Roll Cross and Work Roll Shifting Methods in Cold Strip Rolling, ”Int. J. Met., vol. 2017, pp. 1-10, 2017, doi: 10.1155/2017/6489769.

4. M. Jurkovic, Z. Jurkovic, S. Buljan, and M. Obad, “An experimental and modelling approach for improving utilization rate of the cold roll forming production line," Adv. Prod. Eng. Manag., vol. 13, no. 1, pp. 57-68, 2018, doi: 10.14743/apem2018.1.273.

5. X. Xu, H. Zheng, Z. Guo, X. Wu, and Z. Zheng, “SDD-CNN: Small data-driven convolution neural networks for subtle roller defect inspection," Appl. Sci., vol. 9, no. 7, 2019, doi: 10.3390/app9071364.

6. R. S. Bello, "Development and evaluation of metal rolling machine for small-scale manufacturers," Agric. Eng. Int. CIGR J., vol. 15, no. 3, pp. 80-85, 2013.

7. V. R. Gasyarov, A. A. Radionov, B. M. Loginov, S. S. Voronin, and V. R. Khramshin, "Improvement of work roll bending control system installed at plate mill stand," ACM Int. Conf. Proceeding Ser., vol. Part F1278, pp. 269-273, 2017, doi: 10.1145/3057039.3057105.

8. X. Bin Fan, Y. Zang, Y. K. Sun, and P. A. Wang, "Impact Analysis of Roller System Stability for Four-High Mill Horizontal Vibration," Shock Vib., vol. 2016, 2016, doi: 10.1155/2016/5693584.

9. S. A. Mashekov et al., "Development of New Mill Design and Outgoing Roller Table for Hot Rolling of Thin Strips," vol. 14, no. 4, pp. 2611-2633, 2016.

10. M. Lindgren, Experimental and computational investigation of the roll forming process. 2009.

11. H. Huang, J. Wang, and W. Liu, "Mechanical properties and reinforced mechanism of the stainless steel wire mesh-reinforced Al-matrix composite plate fabricated by twin-roll casting, " Adv. Mech. Eng., vol. 9, no. 6, pp. 1-9, 2017, doi: 10.1177/1687814017716639.

12. S. A. Mashekov, G. A. Smailova, A. M. Alshynova, A. Zhauyt, N. S. Sembaev, and M. R. Maulenova, "Investigation of the formation evolution of aluminum alloy 1050 structure during rolling in the spiral rollers and the longitudinal wedge mill," Metalurgija, vol. 59, no. 2, pp. 203-206, 2020. 
13. D. R. Goyal, A. Joshi, and U. Gurnani, "Review on Cold Rolling Mill Roll Deformation," MATTER Int. J. Sci. Technol., vol. 1, no. 1, pp. 83-95, 2017, doi: 10.20319/mijst.2015.11.8395.

14. A. S. Malik, "Rolling mill optimization using an accurate and rapid new model for mill deflection and strip thickness profile," Convergence, $\quad$ p. $131, \quad$ [Online]. Available: http://rave.ohiolink.edu/etdc/view?acc_num=wright1183664004.

15. X. Song, H. Chen, H. Jiang, X. Xu, Y. Li, and Y. Zhang, "Improved design of roller linear guide for heavy load based on finite element method and measurement," Adv. Mech. Eng., vol. 10, no. 9, pp. 1-8, 2018, doi: $10.1177 / 1687814018800158$

16. P. Szota, D. Strycharska, S. Mróz, and A. Stefanik, "Analysis of rolls wear during the ribbed bars multi-slit rolling process,” Arch. Metall. Mater., vol. 60, no. 2A, pp. 815-820, 2015, doi: 10.1515/amm-2015-0212.

17. V. V. Shokhin and O. V. Permyakova, "The study of continuous rolling mill inter-stand tension inferential control systems," Procedia Eng., vol. 129, pp. 231-238, 2015, doi: 10.1016/j.proeng.2015.12.038.

18. D. C. Wang, H. M. Liu, and J. Liu, "Research and Development Trend of Shape Control for Cold Rolling Strip," Chinese J. Mech. Eng. (English Ed., vol. 30, no. 5, pp. 1248-1261, 2017, doi: 10.1007/s10033-017-0163-8.

19. J. Wang, "Fabrication and angle compensation analysis of skew rolling mill," pp. 1-66, 2014, [Online]. Available: https://lib.dr.iastate.edu/cgi/viewcontent.cgi?referer=https://www.google.com/\&httpsredir $=1 \&$ article $=4934 \&$ context $=$ et $d$.

20. A. Alsamhan, I. Pillinger, and P. Hartely, "The development of real time re-meshing technique for simulating cold-roll-forming using FE methods," J. Mater. Process. Technol., vol. 147, no. 1, pp. 1-9, 2004, doi: 10.1016/S0924-0136(03)00469-2.

21. D. Bhattacharyya, P. D. Smith, S. K. Thadakamalla, and I. F. Collins, "The prediction of roll load in cold roll-forming," J. Mech. Work. Technol., vol. 14, no. 3, pp. 363-379, 1987, doi: 10.1016/0378-3804(87)90019-2.

22. Q. V. Bui and J. P. Ponthot, "Numerical simulation of cold roll-forming processes, ” J. Mater. Process. Technol., vol. 202, no. 1-3, pp. 275-282, 2008, doi: 10.1016/j.jmatprotec.2007.08.073.

23. B. Abeyrathna, B. Rolfe, and M. Weiss, "The effect of process and geometric parameters on longitudinal edge strain and product defects in cold roll forming," Int. J. Adv. Manuf. Technol., vol. 92, no. 1-4, pp. 743-754, 2017, doi: 10.1007/s00170-017-0164-x.

24. M. Lindgren and L. Ingmarsson, "3D roll-forming of hat-profile with variable depth and width," Roll. 1st Int. Congr. Roll Form., 2009. 